\title{
Application of Novel Printed Dipole Antenna to Design Broadband Planar Phased Array
}

\author{
Jie Xu and Wenbin Dou \\ State Key Laboratory of Millimeter Waves, Southeast University, Nanjing 210096, China \\ Correspondence should be addressed to Jie Xu; xujie15617953@163.com
}

Received 22 October 2013; Accepted 30 December 2013; Published 10 February 2014

Academic Editor: Shaoqiu Xiao

Copyright ( $92014 \mathrm{~J}$. Xu and W. Dou. This is an open access article distributed under the Creative Commons Attribution License, which permits unrestricted use, distribution, and reproduction in any medium, provided the original work is properly cited.

\begin{abstract}
A broadband planar phased array consisting of 22 linear printed dipole antennas (PDA) is presented in this paper. The element is designed by a coax probe feeding mechanism with a ground plate configuration. The PDA with two arms placed on both sides of a substrate is realized. The inner conductor of the coaxial cable is connected to the PDA's upper arm, and the outer conductor is connected to the PDA's lower arm, so it eliminates the balun. The impedance bandwidth of the PDA array can be improved by increasing mutual coupling effect between the adjacent array elements. A dielectric layer, which is integrated on the surface of the antenna, is designed and fabricated to improve the impedance bandwidth and to shield the array. The measured results indicate the active VSWR is less than 3 over the frequency range of $4-20 \mathrm{GHz}$.
\end{abstract}

\section{Introduction}

In recent years, the demand for broadband phased arrays, which are capable of large scan volumes and suitable for conformal applications, is steadily increasing due to the desire to replace multiple sensors with a single multifunction aperture in a low-profile installation, provide higher data rates, and operate over a wide field of view. In general, the technology of phased array antenna which is based on Vivaldi antenna [1-3] or microstrip patch antenna $[4,5]$ is mature. Unfortunately, the Vivaldi antenna is not easy to be coplanar, and bandwidth of microstrip patch antenna is not wide.

To solve the problem, a methodology of forming broadband array from tightly-coupled, electrically small elements has been proven by other researchers [6-8]. Harris has demonstrated that the current sheet array (CSA) technology can be applied to a wide range of frequency bands and array sizes. The active VSWR is 3 or better over the entire 2$18 \mathrm{GHz}$ band [9]. Furthermore, Durham invented a new CSA structure to solve the problem [10]. Each dipole antenna element comprises a medial feed portion, and a pair of legs extending outwardly therefrom, and adjacent legs of adjacent dipole antenna elements include respective spaced apart end portions. A respective impedance element is electrically connected between the spaced apart end portions of adjacent legs of adjacent dipole antenna elements for providing increased capacitive coupling therebetween. However, there is a shortcoming in the structure. Balun is needed to achieve the connection between the element and the coax probe in the antenna structure, which is hard to design when the space between the elements is small.

In order to eliminate the balun, the paper gives another method to form broadband array from tightly coupled elements. The structure is different from the CSA. First, the inner conductor of the coaxial cable is connected to the PDA's upper arm, and the outer conductor is connected to the PDA's lower arm, so eliminate the balun. Second, the implementation of the interelement coupling was accomplished using flat capacitors. In this paper, a planar linear phased array antenna with 22 elements is designed and fabricated. The measured results indicate the active VSWR is less than 3 over the frequency range of $4-20 \mathrm{GHz}$.

\section{Antenna Element Design}

The structure of the center antenna element in infinite array along $y$-direction is shown in Figure 1. The antenna element is composed ofa dielectric layer, PDA, a feeding coaxial cable, and a ground plate. The element is designed by a coax probe 


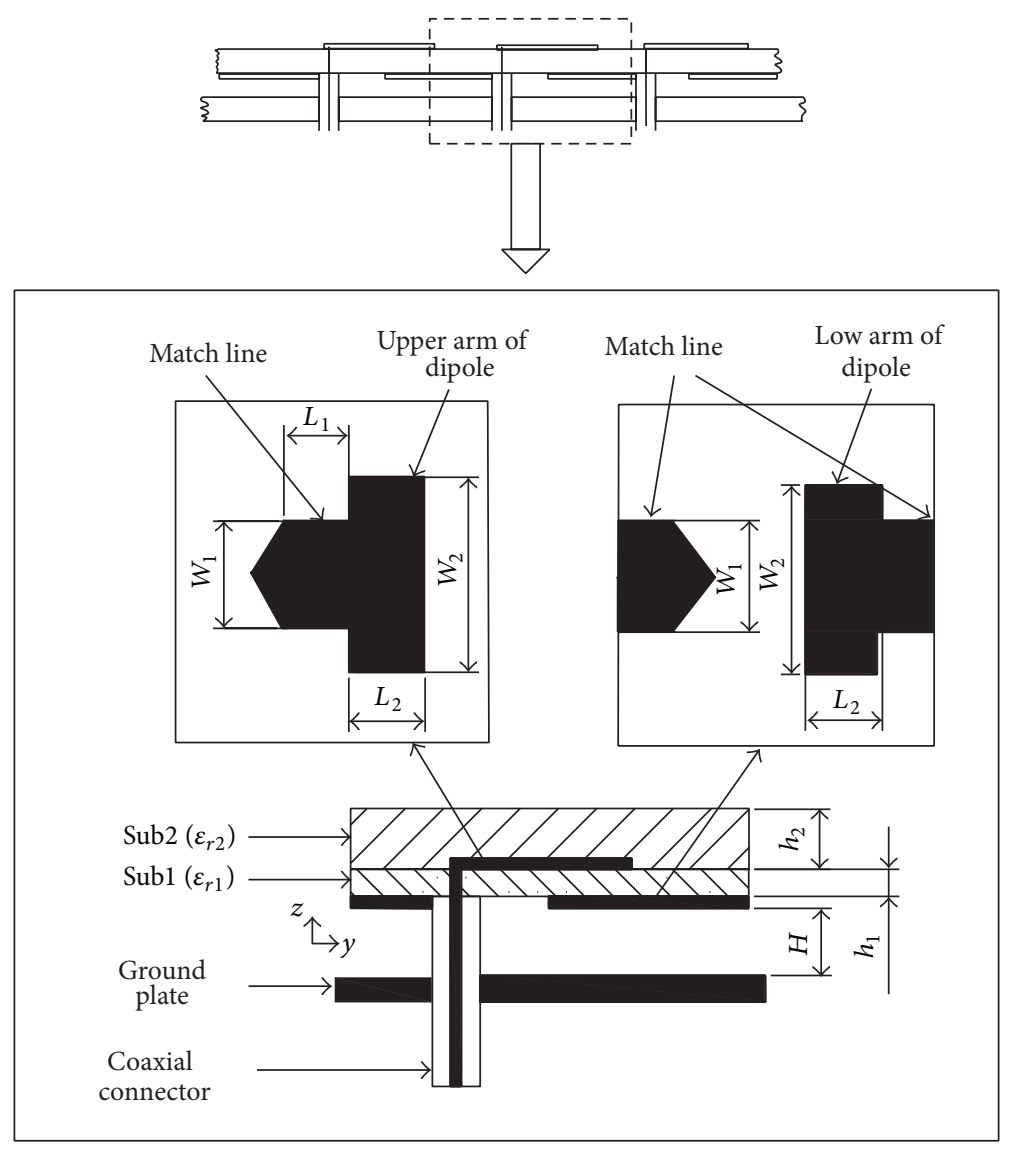

FIGURE 1: Structure of the center antenna element in infinite array.

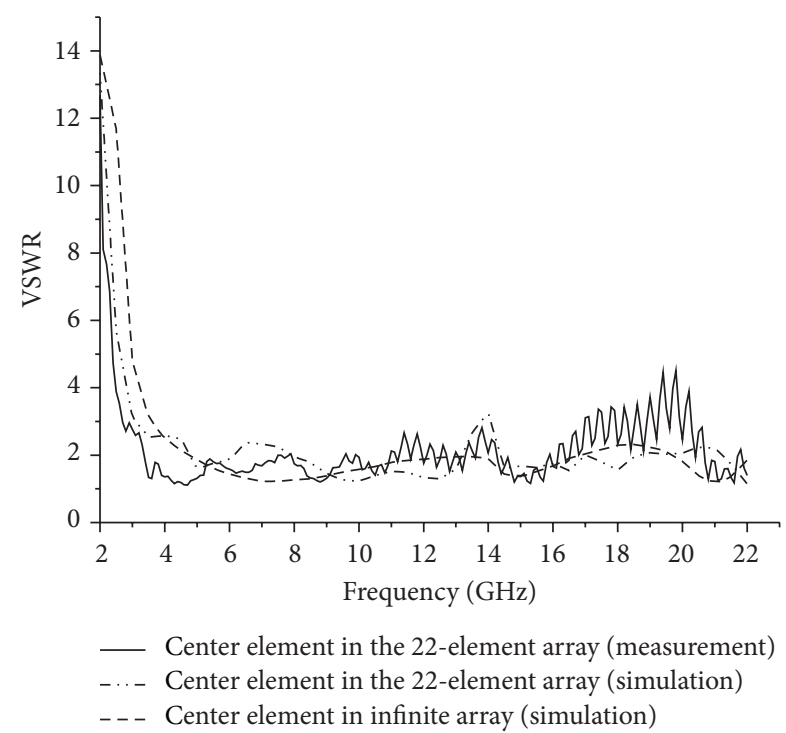

FIGURE 2: Simulated active VSWR of the center element in infinite array.

feeding mechanism with a ground plate configuration. The PDA with two arms placed on both sides of a substrate is realized. The inner conductor of the coaxial cable is

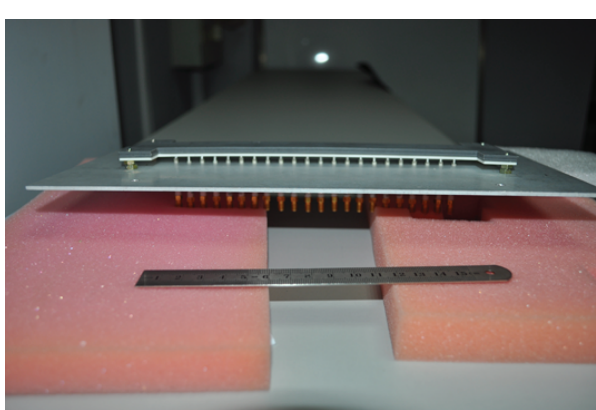

(a)

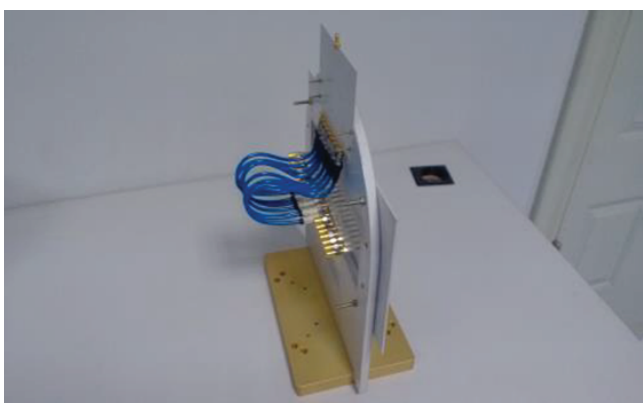

(b)

FIGURE 3: Prototype planar phased array antenna. (a) Array antenna and (b) Array antenna with the power divider. 


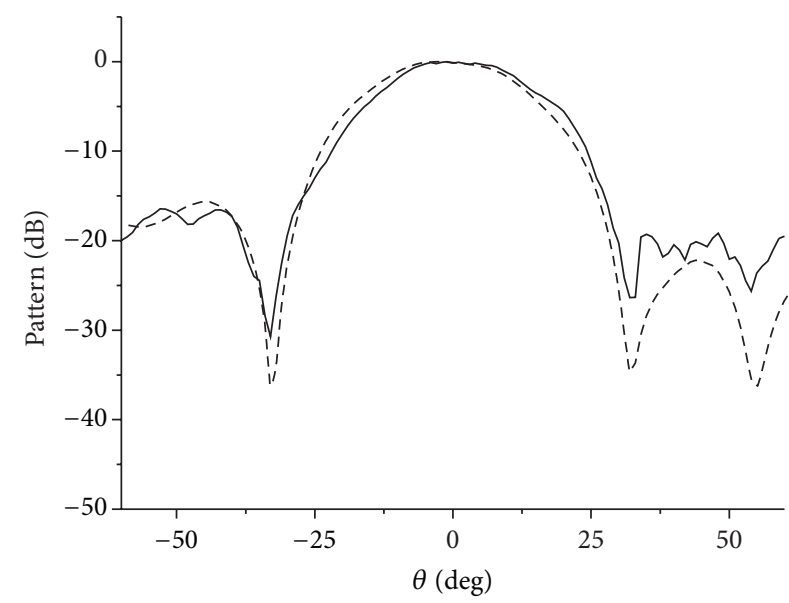

(a) E-plane at $8 \mathrm{GHz}$

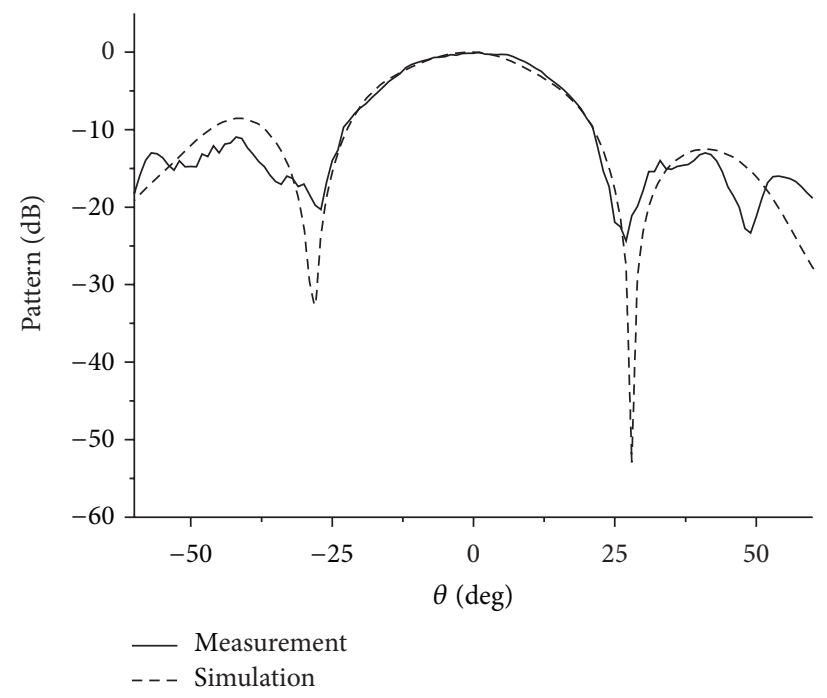

(c) E-plane at $9 \mathrm{GHz}$

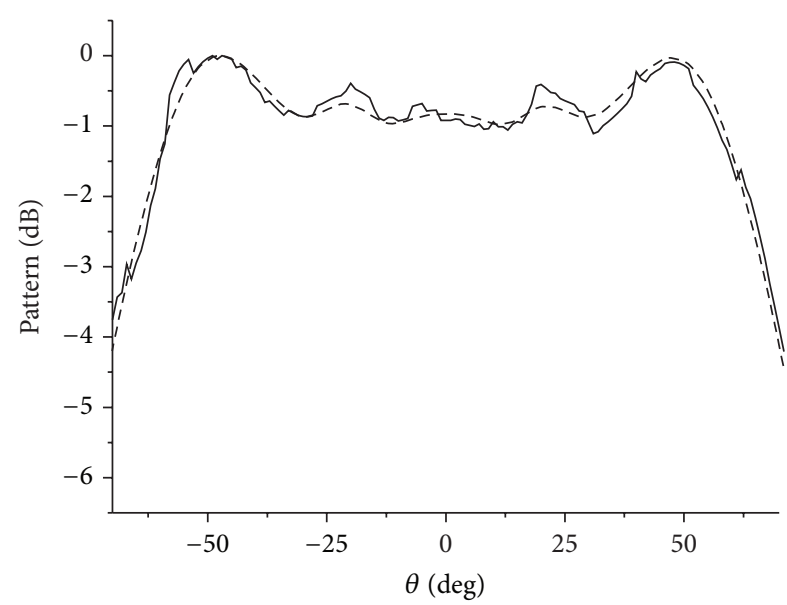

(b) $H$-plane at $8 \mathrm{GHz}$

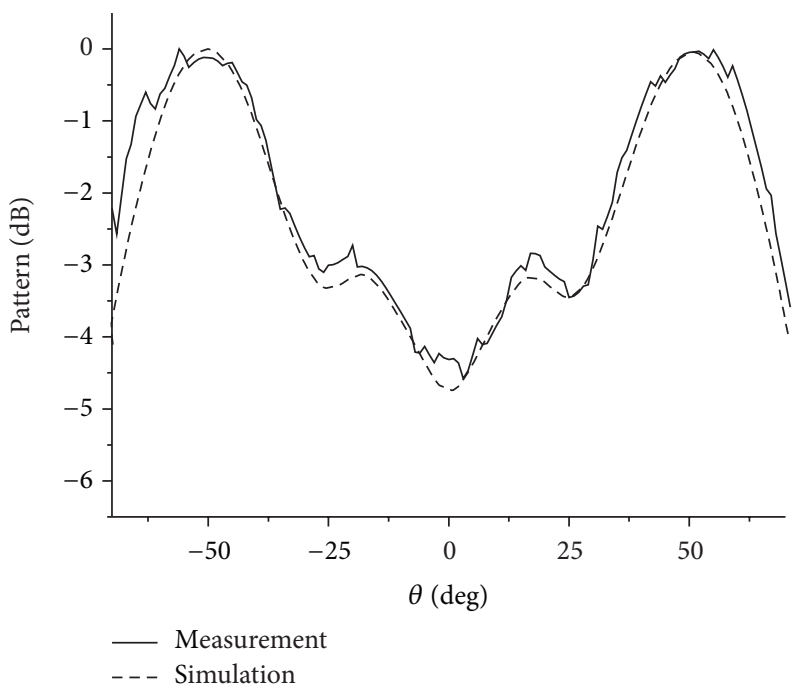

(d) $H$-plane at $9 \mathrm{GHz}$

FIGURE 4: Measured and simulated radiation patterns of the center linear 8-element array at different frequencies. (a) $E$-plane at 8 GHz. (b) $H$-plane at $8 \mathrm{GHz}$. (c) E-plane at $9 \mathrm{GHz}$. (d) $H$-plane at $9 \mathrm{GHz}$.

connected to the PDA's upper arm, and the outer conductor is connected to the PDA's lower arm, so it eliminates the balun.

The parameters of two substrate layers are $h_{1}, h_{2}, \varepsilon_{1}$, and $\varepsilon_{2}$, respectively. The size of match line is $W_{1} \times L_{1}$, and the size of arm is $W_{2} \times L_{2}$. The distance between its PDA and ground plate is $H$. The antenna is symmetrically relative to the center antenna. Besides, there is a feed coaxial cable located in the center line of the antenna.

The arms of adjacent array elements constitute flat capacitors, which improve the impedance bandwidth by operating strong capacitive-couple effect. However, there are some differences between this type of elements and the antenna mentioned in [9]. First, the inner conductor of the coaxial cable is connected to the PDA's upper arm, and the outer conductor is connected to the PDA's lower arm, so eliminate the balun. Second, the implementation of the interelement coupling is accomplished using flat capacitors as shown in Figure 1, while the CSA is using interdigital capacitors in [9].
The design way is performed using the periodic moment method (PMM) code, which can analyze infinitely periodic planar structures comprised of thin wires and lumped circuit element surrounded by dielectric layers [10].

To analyze the effects of the mutual coupling on the matching of the center element in infinite array, the active VSWR of the center element within the mutual coupling effect is simulated by HFSS. By adjusting the thickness of Sub2 and the size of the match line, the discontinuity will be compensated, which leads to a nice performance of impedance match. The optimized thickness of Sub2 is $4 \mathrm{~mm}$, and the size of the match line is $8.5 \mathrm{~mm} \times 1.5 \mathrm{~mm}$. The other parameters are as follows: $H=6 \mathrm{~mm}, h_{1}=1.5 \mathrm{~mm}$, and $\varepsilon_{1}=3.35, h_{2}=4 \mathrm{~mm}, \varepsilon_{2}=2.2$. The length of the periodical center element in infinite array is $8.7 \mathrm{~mm}$. The array lattice of $8.7 \mathrm{~mm}$ allows the main beam to be scanned between $-30^{\circ}$ and $30^{\circ}$ over the frequency of $4-20 \mathrm{GHz}$ without grating lobs. So the center element can be simulated easily in an infinite 


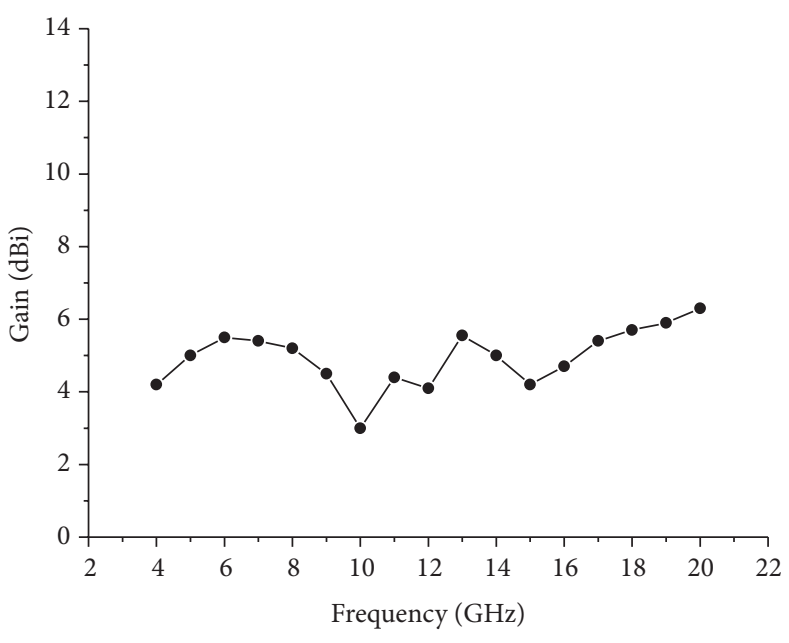

(a)

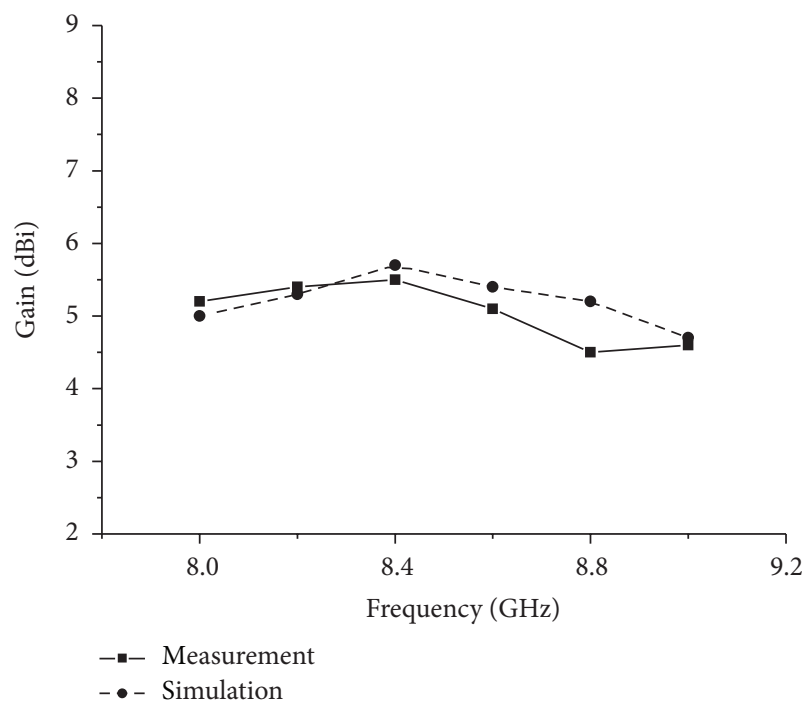

(b)

FIGURE 5: (a) Simulated gain of the center 8-element array over the range of 4-20 GHz. (b) Measured and simulated gain of the center 8 element array from $8 \mathrm{GHz}$ to $9 \mathrm{GHz}$.

environment. As can be seen from the results in Figure 2, the operation bandwidth (the active VSWR $<3$ ) of the center element in infinite array is from 4 to $20 \mathrm{GHz}$.

\section{Planar Phased Array Antenna Construction and Measured Results}

A prototype planar antenna built up by 22 elements proposed in Section 2 is fabricated along the $y$-direction, which is shown in Figure 3. The space between the element is $8.7 \mathrm{~mm}$. Each element is equal, and its parameters are the same as the above antenna element. The measured and simulated active VSWR of the center embedded in 22-element array is shown in Figure 2. The measured bandwidth of VSWR less than 3 is from 4 to $20 \mathrm{GHz}$. Compared to the simulated result, there is a certain fluctuation in high frequency due to the material of Sub2 (FB4M), which can do well only under $12 \mathrm{GHz}$. What is more, these results indicate that the matching characteristic of the center element in large array can be estimated through the center element in infinite array, which is advantageous to decrease the difficulty of the model construction and the requirements for the computing devices. The fabrication and construction errors will also result in the deterioration of the antenna performance. The errors are mainly caused by the displacement of the layers in this antenna.

In order to verify the center 8-element linear array's radiation characteristic (the rest element match to the load), 8 -way power divider is designed and processed over the frequency range of $8 \mathrm{GHz}-9 \mathrm{GHz}$. The radiation of the center linear array is measured with an 8-way power divider, whose results are shown in Figure 4 . The measured results are similar to the simulated results, which present a pretty radiation characteristic at $f=8 \mathrm{GHz}$ and $f=9 \mathrm{GHz}$. The maximum relative sidelobe level in the $E$-plane is $-16.5 \mathrm{~dB}$ at $f=8 \mathrm{GHz}$ and $-12.5 \mathrm{~dB}$ at $f=9 \mathrm{GHz}$. Because of the bandwidth limit of the power divider (range of $8-9 \mathrm{GHz}$ ), the paper gives the simulated gain of the center 8-element array over the range of 4-20 GHz and only gives the measured gain of 8-element array from $8 \mathrm{GHz}$ to $9 \mathrm{GHz}$, whose results are shown in Figure 5. The simulated gain is comparatively stable in the operation bandwidth, and the maximum value is $6.45 \mathrm{dBi}$ at $20 \mathrm{GHz}$. The measured gain $(8-9 \mathrm{GHz})$ is similar to the simulated results.

\section{Conclusions}

The novel ground-backed PDA represents a significant departure from the conventional approach to phased array design, which is utilized for the element due to its ability to compensate for the impedance variation with frequency. The structure is different from the CSA. First, the inner conductor of the coaxial cable is connected to the PDA's upper arm, and the outer conductor is connected to the PDA's lower arm, so eliminate the balun. Second, the implementation of the interelement coupling was accomplished using flat capacitors. The measured results indicate that the array has a wide bandwidth and a pretty radiation. It is adapted to build up the planar phased array systems.

\section{Conflict of Interests}

The authors declare that there is no conflict of interests regarding the publication of this paper.

\section{References}

[1] W. Mohuchy, P. A. Beyerle, and A. B. MacFarland, " $4.5: 1$ bandwidth microstrip notch array measured performance," 
in Proceedings of the IEEE Antennas and Propagation Society International Symposium, pp. 444-447, July 2001.

[2] M. Kragalott, W. R. Pickles, and M. S. Kluskens, "Design of a $5: 1$ bandwidth stripline notch array from FDTD analysis," IEEE Transactions on Antennas and Propagation, vol. 48, no. 11, pp. 1733-1740, 2000.

[3] R. Thomas Dover, J. lrion II, D. T. McGrathm, and N. Schuneman, "Ultra-wideband arrays Phased Array Systems and Technology," in Proceedings of the International Symposium on Phased Array Systems and Technology, vol. 1, pp. 387-392, 2003.

[4] A. M. Ferendeci, "Conformal wide bandwidth antennas and arrays," in Proceedings of the 3rd IEEE International Symposium on Microwave, Antenna, Propagation and EMC Technologies for Wireless Communications (MAPE '09), pp. k7-k10, October 2009.

[5] M. Geissler, F. Woetzel, M. Bottcher et al., "Design and test of an L-band phased array for maritime satcom," in Proceedings of the 5th European Conference on Antennas and Propagation (EUCAP '11), pp. 2871-2875, April 2011.

[6] B. A. Munk, Frequency Selective Surfaces: Theory and Design, chapters 3-4, Wiley-Interscience, New York, NY, USA, 2000.

[7] J. G. Maloney, M. P. Kesler, P. L. H. Harms, and G. S. Smith, "Fragmented aperture antennas and broadband antenna ground planes," US Patent 6,323,809, November 2001.

[8] S. H. Wi, Y. S. Lee, and J. G. Yook, "Wideband microstrip patch antenna with U-shaped parasitic elements," IEEE Transactions on Antennas and Propagation, vol. 55, no. 4, pp. 1196-1199, 2007.

[9] W. A. Davis, J. R. Nealy, G. F. Ricciardi, and W. L. Stutzman, "Techniques for the measurement of the impedance of wideband balanced antennas," in Proceedings of the IEEE Antenna Measurement Techniques Association Symposium, November 1995.

[10] T. E. Durham, G. K. Gothard, A. M. Jones, and J. Kralovec, "Phased array antenna with discrete capacitive coupling and associated methods," US Patent 6,856,297, February 2005. 

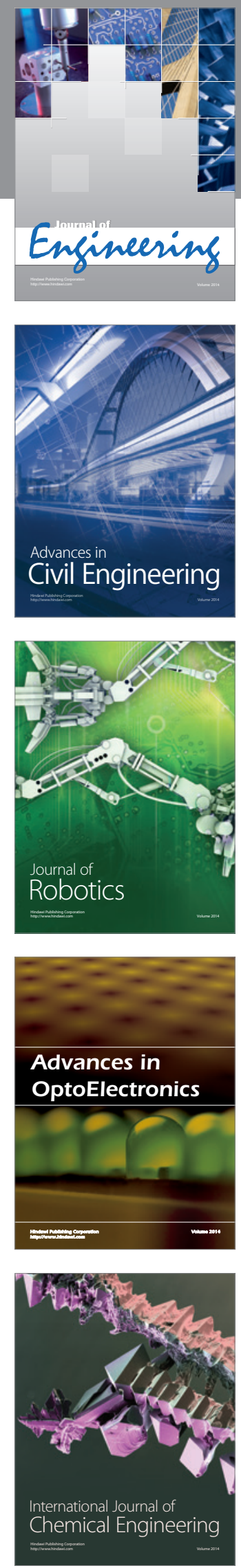

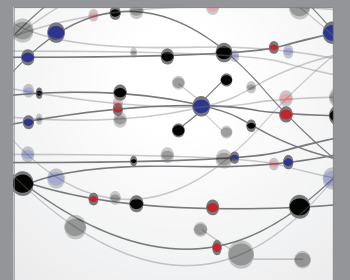

The Scientific World Journal
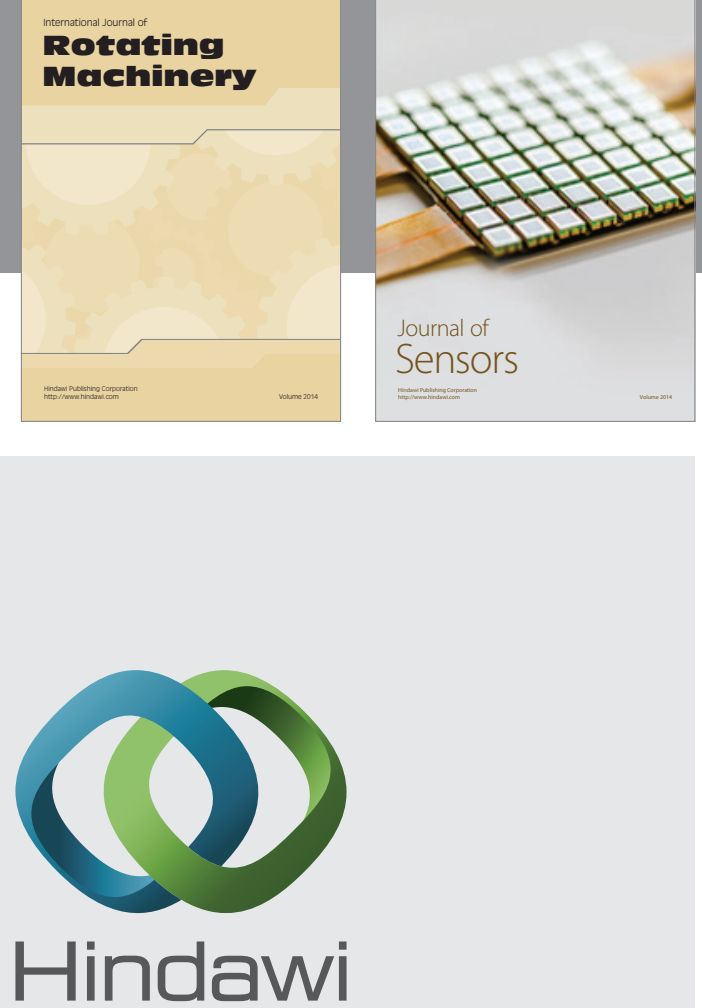

Submit your manuscripts at http://www.hindawi.com
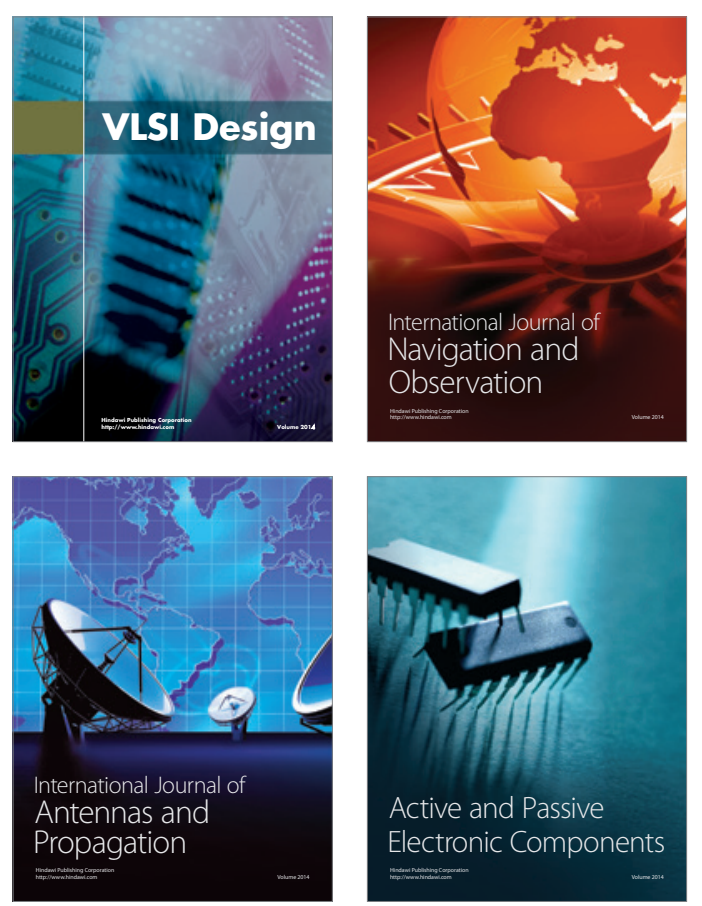
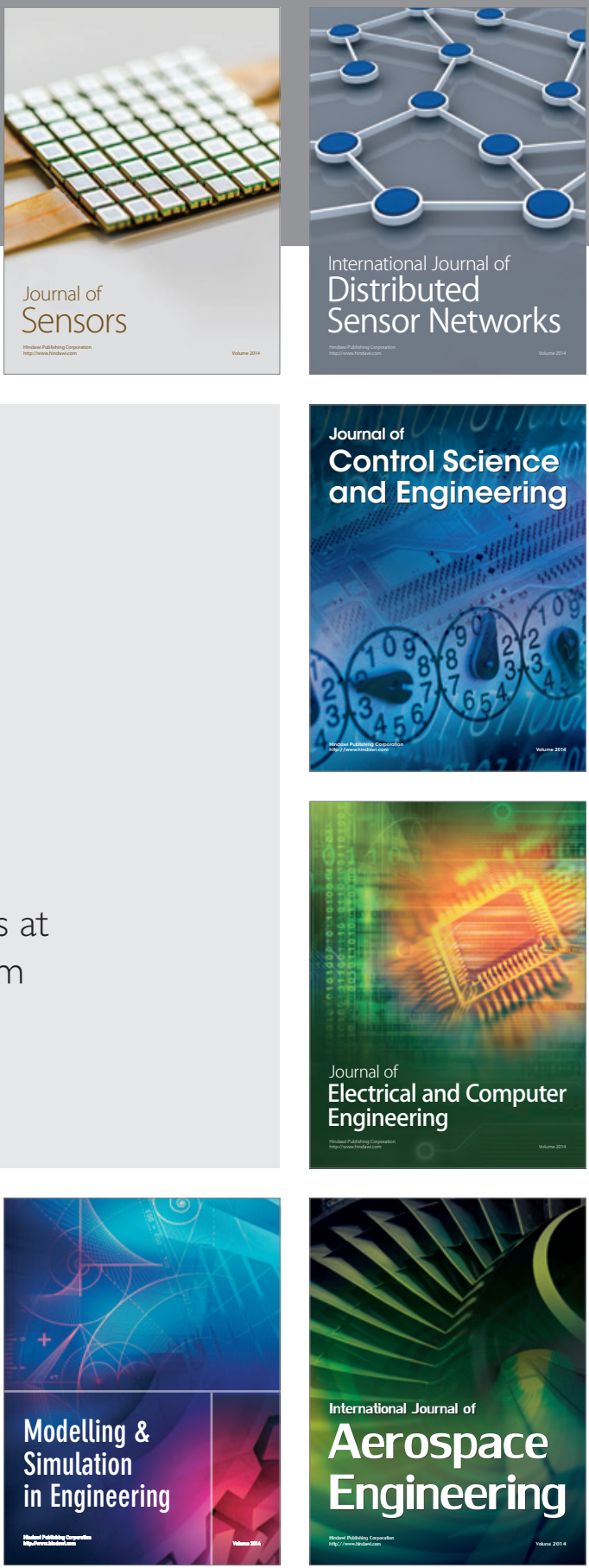

Journal of

Control Science

and Engineering
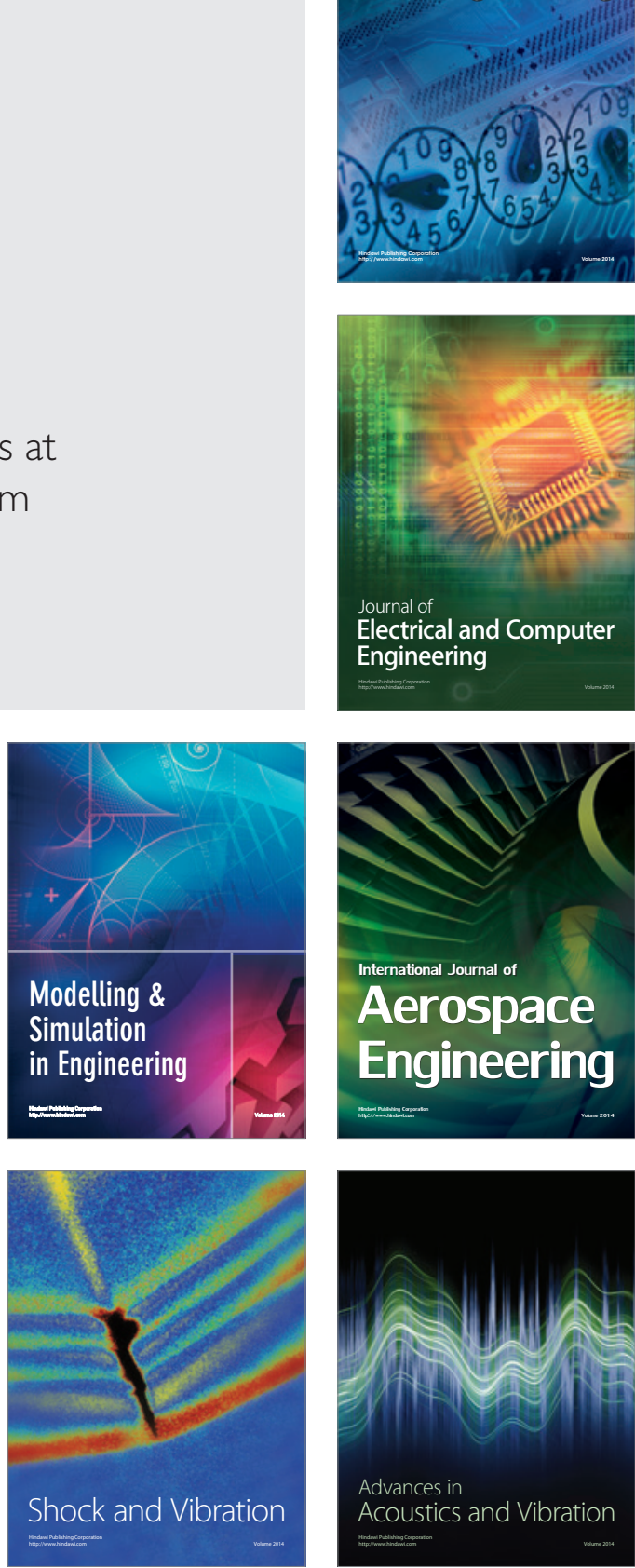